\title{
THE PHYSICOCHEMICAL BASES OF OIL AND OIL PRODUCTS ABSORPTION BY GLASSY SORBENTS
}

\author{
Vadim E. Kogan, Petr V. Zgonnik ${ }^{\bowtie}$, Tamara S. Shakhparonova, Daria O. \\ Sobianina and Zinaida V. Suvorova \\ Saint-Petersburg Mining University, 21st Line, 2, St. Petersburg 199106, Russia \\ ${ }^{\square}$ Corresponding Author: piter_cat@mail.ru
}

\begin{abstract}
The article presents a study of using foam glass as oil sorbents. The main object of these studies was glassy foams of inorganic (glass) and organic nature. The foam glass of the Gomelsteklo PLC was chosen for the experiment, which is due to the use of coal as a gas generator in its production. The oil used was REBCO (Russian Export Blend Crude Oil). Diesel fuel ULSD 10ppm (Ultra Low Sulfur Diesel) with a sulfur content of $10 \mathrm{mg} / \mathrm{kg}$ was used as a petroleum product. The obtained experimental results have allowed formulating the necessary as well as the necessary and sufficient conditions for the existence of peaks on the absorption kinetic curves for these sorbents in the initial period and identifying the factors that determine the height of the mentioned peaks and the maximum capacity of sorbents to oil and oil products (diesel fuel).

Keywords: Oil Sorbents, Kinetics of Oil Sorption, Chemical Microinhomogeneity, Capillary Potential.
\end{abstract}

RASĀYAN J. Chem., Vol. 14, No.3, 2021

\section{INTRODUCTION}

Oil chemical composition and its properties determine the hazard posed by oil pollution to the environment. In contact with water, oil forms emulsions or films floating on the surface of the water. A significant share of the heteroatomic compounds in oil composition belongs to base nitrogen-containing compounds, carboxylic and naphthenic acids, their esters, and aldehydes and ketones. All of them are in varying degrees soluble in water. Therefore, even very low concentrations of oil may be toxic to aquatic organisms. Another serious threat to the environment comes from polycyclic aromatic hydrocarbons, which affect various biological processes that are carcinogenic, and may have a powerful mutagenic effect on living organisms. As a result of oil weathering, during which light fractions of oil evaporate into the atmosphere, the content of the most dangerous substances in the oil increases, which, following the distribution law, pass into the phase contacting with the oil, for example, into the water where an oil spill occurred, in greater quantities.

Currently, people at public and governmental levels have become aware of the need to care for nature and to develop specific actions for protecting nature from pollution by oil and oil products and preserving the environment. Water contamination by oil spills causes the most significant harm to the environment, affects human health, has a negative economic effect, and is much more difficult to remove, compared to oil contamination of the land.

Certain emergencies occur almost inevitably in oil production, storage, and transportation, resulting in occasional oil and oil product spills into the environment. Among them, the most extensive and serious consequences are emergencies during oil transportation by tankers in the areas of intensive navigation, and adverse navigation conditions.

The methods of removing water surface pollution by the oil may be divided into the following four main groups: $:^{1,2}$ mechanical, performed with the use of various oil collecting structures and devices; physicochemical, based on the use of physicochemical phenomena, absorption, in particular, biological, implemented using microbiological cultures and photochemical reactions that occur under the action of sunlight and catalysts. The advantages of the sorption method include the possibility of removing contaminations of extremely extensive nature down to almost any residual concentration, regardless of their chemical resistance, the absence of secondary pollution, and process control. 
The market of industrial oil sorbents is characterized by a wide diversity. At the same time, their practical use is very limited. This is mainly because oil sorbents are mainly developed through trial and error. This is clear evidence of the relevance of creating the theoretical bases for the purposeful synthesis of new effective oil sorbents.

Work $^{3}$ states that over 300 companies in the world produce oil sorbents (or, at least, claim that they can do that). At the same time, as indicated in article ${ }^{4}$, only a few dozen product names are known in the market. Despite the large number of works devoted to the development of oil sorbents, the main obstacle for their effective use, in the opinion of the authors, is the lack of theoretical bases for the synthesis of oil sorbents with a predetermined set of physical and chemical properties and operating parameters, and the non-use of a wide range of materials for obtaining oil sorbents.

In this aspect, the most unexplored is foam glass - a unique material $100 \%$ made of glass cells that were created in the 1930s in the USSR (ex-MChTI n.a. D. I. Mendeleev, today is - Mendeleev University of Chemical Technology of Russia) and in the early 40s in the United States (the Corning Glass Works company). The initial intention was to use foam glass as a buoyant material, and buoyancy is one of the essential characteristics of oil sorbents.

All previously mentioned resulted in starting the work aimed at overcoming this drawback at the St. Petersburg Mining University in 2012 under the leadership of Professor V. E. Kogan. The main objects of these studies were glassy inorganic (glass) and organic forms.

\section{Material and Methods}

\section{EXPERIMENTAL}

The used oil was REBCO (Russian Export Blend Crude Oil) oil 2.2 E. 1.1 Russian State Standard GOST R 51858 - the grade of Russian exported oil mixture formed in the Transneft pipeline system by mixing heavy sour oil from the Volga-Ural region and sweet crude oil from Western Siberia the characteristics of which corresponded to those of grade Urals, exported from the Russian Federation through the ports in Primorsk and Ust-Luga. The oil product used was diesel fuel ULSD 10 ppm (Ultra Low Sulfur Diesel) with the content of sulfur of $10 \mathrm{mg} / \mathrm{kg}$ - the EURO diesel fuel, grade C, type III (DT-L-K5) GOST R 52368-2005 (EN 590:2009).

The efficiency of the sorbents (absorption of oil and diesel fuel, buoyancy) was assessed according to Russian Technical specifications TU 214-10942388-03-95 "Assessment of the efficiency of sorbents". This method was discussed in detail in work ${ }^{1}$.

The X-ray diffraction analysis was performed on an x-ray diffractometer DRON-7 with a parabolic mirror, which provided sample irradiation with a low divergence (less than 0.1') paraxial beam. Therefore, the width of the diffraction peaks characterizes only the dimensions of the crystallites. Measurement was performed under monochromatic X-ray radiation $\mathrm{CuK}_{\alpha 1}$ with the wavelength $\lambda=$ $1.5406 \AA$.

Electron microscopic studies were performed on scanning electron microscope Supra 55 VP made by the Carl Zeiss company (Germany). The samples used for electron microscopic research were platinum plated on the Q150T installation for high-vacuum spattering made by Quorum Technologies Company (UK).

To measure the surface area and the porosity of sorbents, a gas absorption analyzer Quantachrome NOVA 4200e with NOVA Win-2.1 software made by the Quantachrome Instruments Company (USA) was used.

\section{RESULTS AND DISCUSSION}

Foam glass had never been studied as an oil sorbent before works. ${ }^{2,4}$ From the entire range of foam glass mentioned in these works and produced by the industry, the authors chose the foam glass made by LLC Gomelglass, since a coal gasifier was used in its production. The glass obtained without violation of technological conditions is black, which is evidence of the localization of residual carbon on the surface ${ }^{5}$, which has well-known good water-repellent and absorption properties.

The most interesting results were obtained in studying oil absorption. For all known oil sorbents ${ }^{6-8}$, the kinetic curves were characterized by increased oil absorption with subsequent absorptive saturation. However, for the studied foam glass with the fraction size of 3-8 $\mathrm{mm}$, the absorption kinetics in the initial period is characterized by the presence of a peak. Such dependencies had not been known in the literature. 
The results of the studies, given the established similar kinetic dependence for the samples of foam glass with the fraction size of 3-8 mm obtained in the laboratory without the use of coal and not subjected to hydrophobization, are evidence of the fact that the nature of the dependencies is determined by the features of the vitreous state.

Further studies of inorganic glassy sorbents were performed with the foam glass obtained in the laboratory from various classes of glass produced in industrial conditions. ${ }^{9-19}$ For obtaining foam glass, various technological formulation parameters were used, and before the study, the surface "crust" was removed from them. The obtained sorbents were virtually unsinkable.

For all studied objects, it was found that when glassy sorbents with the fraction size of 3-8 mm were used, peaks were observed on the absorption kinetic curves for oil and diesel fuel (in case of studying the latter), which were absent in studying isolated or crystallized samples with the same composition.

The adsorbents based on the glass $\mathrm{K}_{2} \mathrm{O}-(\mathrm{Mg}, \mathrm{Ca}) \mathrm{O}-\mathrm{P}_{2} \mathrm{O}_{5}$, which were of great practical interest, were studied in most detail. The fact is that their use removes the problem of regeneration of the sorbent, which becomes suitable for repeated use. Indeed, after the process of absorption, the sorbent with oil may be poured onto the ground, and associations of hydrocarbons destructor strains may be applied to it. After that, the sorbent may be used again, or it may be used as the AVA fertilizer. ${ }^{20,21}$

In work ${ }^{19}$, it was found that in the production of oil sorbents based on phosphate glass, the use of substances that resulted in the formation of new structural fragments, i.e., increased the extent of chemical microheterogeneity, resulted in increasing the height of the peak on the oil absorption kinetic curve. It was also found that the maximum oil absorption by sorbents is a function of the volume concentration of micro-and mesopores. Increasing the mesopores volume concentration (decreasing the volume concentration of micropores) increases the oil capacity of the sorbents.

At the same time, for the sorbents studied in $\operatorname{work}^{19}$, the nature of oil products (diesel fuel) absorption kinetic curves had not been explored before this study. The results of this study are shown in Figs.-1 and 2.

As can be seen in Fig. 1 , a peak with the height of $h_{1}=h_{2}=h_{3}=0.1$ g/g is observed for all sorbents (regardless of the amount of peat used) on the diesel fuel absorption kinetic curves, while the height of the peak is $\mathrm{h}_{4}=0.28 \mathrm{~g} / \mathrm{g}$ (Fig.-2), which correlates with the data about oil absorption given in work ${ }^{19}$, and allows to generalize the conclusion made in it about increasing the height of the peak on the oil absorption kinetic curve with increasing the degree of chemical microheterogeneity and diesel fuel absorption. With that, it should be stated that the observed facts are most likely related to increasing the nonequipotentiality of the surface with increasing the degree of chemical microheterogeneity, which causes an increase in the capillary potential in the capillaries with a vitreous surface (in particular, in the porosity space between the samples). This is also supported by the shift of both oil and diesel fuel absorption peaks from 10 to 5 minutes.

Studying the kinetics of diesel fuel absorption by the sorbents in question also shows the validity of the conclusion of work ${ }^{19}$ about the effect of volume concentration of mesopores on the maximum oil capacity and concerning the maximum capacity for absorbing diesel fuel. Indeed, for the sorbents with $4 \mathrm{~g}, 2 \mathrm{~g}$, and $1 \mathrm{~g}$ of peat, and the sorbent with $1 \mathrm{~g}$ of peat and $10 \mathrm{~g}$ of boric acid per $100 \mathrm{~g}$ of glass, according to work $^{19}$, the volume concentration of mesopores increased in the row of $63.37 \%, 65.78 \%, 70.17 \%$, and $80.50 \%$, while the maximum capacity for diesel fuel was $0.55 \mathrm{~g} / \mathrm{g}, 0.80 \mathrm{~g} / \mathrm{g}, 0.90 \mathrm{~g} / \mathrm{g}$, and $1.08 \mathrm{~g} / \mathrm{g}$, respectively (Fig.-1 and 2).

Based on the results obtained in studying the kinetics of oil and diesel fuel absorption by sorbents made of foam glass, the question arose whether the nature of kinetic dependences of oil and diesel fuel absorption obtained for them was the result of peculiarities of inorganic vitreous state, or whether it was characteristic to any vitreous state. To answer this question, the authors initially performed a study, in which the objects were organic polymer materials — solid (rigid) polyurethane foams (PUF) of two types: glassy PUF made by the Polyprom Company from Saint-Petersburg (further referred to as PUFPeter) used as building insulation, and crystalline PUF made by the Belarusian-American JV TSIN EST TRADE, LLC, Minsk (further referred to as PUF-Minsk), positioned by the producer as cosmetic pumice $^{2,22}$. 
Samples of PUF-Peter with the fraction size of 3-8 $\mathrm{mm}$ (both hydrophobized and not hydrophobized) had the nature of the oil absorption kinetic curves similar to the one obtained for the oil absorbents made of foam glass. This allowed concluding that the specific nature of oil absorption kinetic curves was determined by the glassy state of the surface of the sorbent samples, regardless of its nature (inorganic or organic).

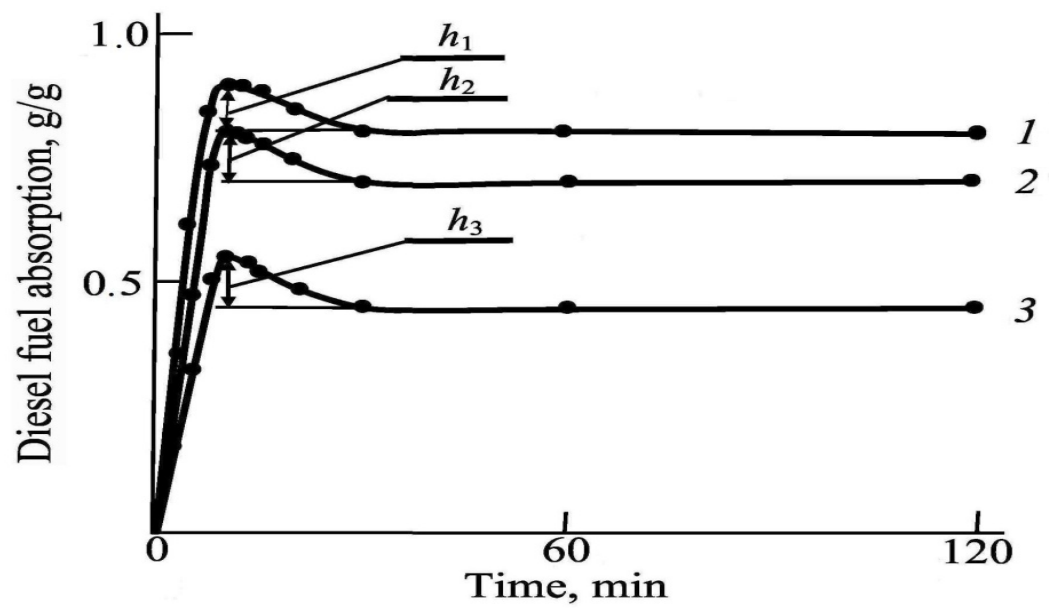

Fig.-1: Kinetics of Diesel Fuel Absorption of Sorbents of the 3-8 mm Fraction obtained with the use of Peat: $1-1 \mathrm{~g}$ per $100 \mathrm{~g}$ of Glass; $2-2 \mathrm{~g}$ per $100 \mathrm{~g}$ of Glass; and $3-4 \mathrm{~g}$ per $100 \mathrm{~g}$ of Glass

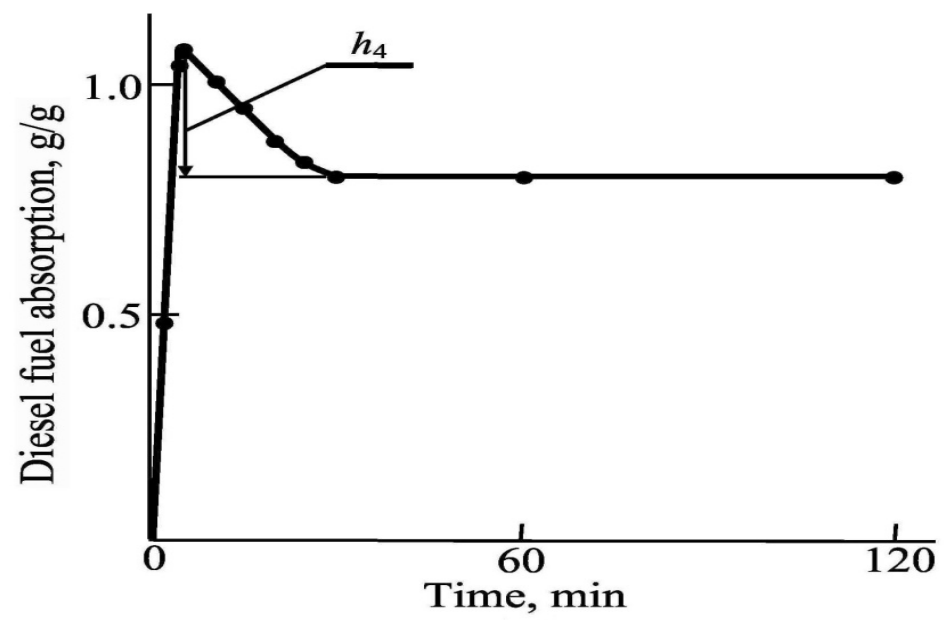

Fig.-2: Kinetics of Diesel Fuel Absorption by Samples of Sorbent of 3-8 mm Fraction of Phosphate Foam Glass obtained by using $1 \mathrm{~g}$ of Peat and $10 \mathrm{~g}$ of Orthoboric Acid per $100 \mathrm{~g}$ of Glass

This conclusion was confirmed by the results of studying the kinetics of oil absorption by the samples of PUF-Minsk with the fraction size of 3-8 mm. For the samples without the hydrophobization, the oil absorption kinetic curve was identical for all known sorbents (e.g., see works ${ }^{6-8}$ ), while for the samples subjected to hydrophobization, it was identical to the kinetic curve for the samples of PUF-Peter and foam glass. We believe that this was due to the thermal stage of the hydrophobization process, the temperature of which reached about $330 \mathrm{~K}$, while the temperature of polyurethanes vitrification was 226-356 K. Thus, in the process of hydrophobization, the transition from crystalline to a glassy state was observed. The rate of subsequent cooling was sufficient for its further preservation.

Even the considered studies of inorganic and organic oil adsorbents allowed formulating the necessary condition for the existence of a peak on the oil absorption kinetic curves - the glassy nature of their surface.

To check whether the glassy nature of the oil sorbents surface is also a sufficient condition for the existence of a peak on the oil absorption kinetic curves, the authors studied ${ }^{23}$ the kinetics of absorption by 
RASĀYAN J.Chem.

Vol. 14 | No. 3 |2006-2016| July - September | 2021

a single PUF-Peter sample (Figure 3 a). For this sample, like for the single studied samples of oil sorbents based on valve-bulb glass $\mathrm{C} 95-2^{23}$, no peak was observed on the oil absorption kinetic curve.
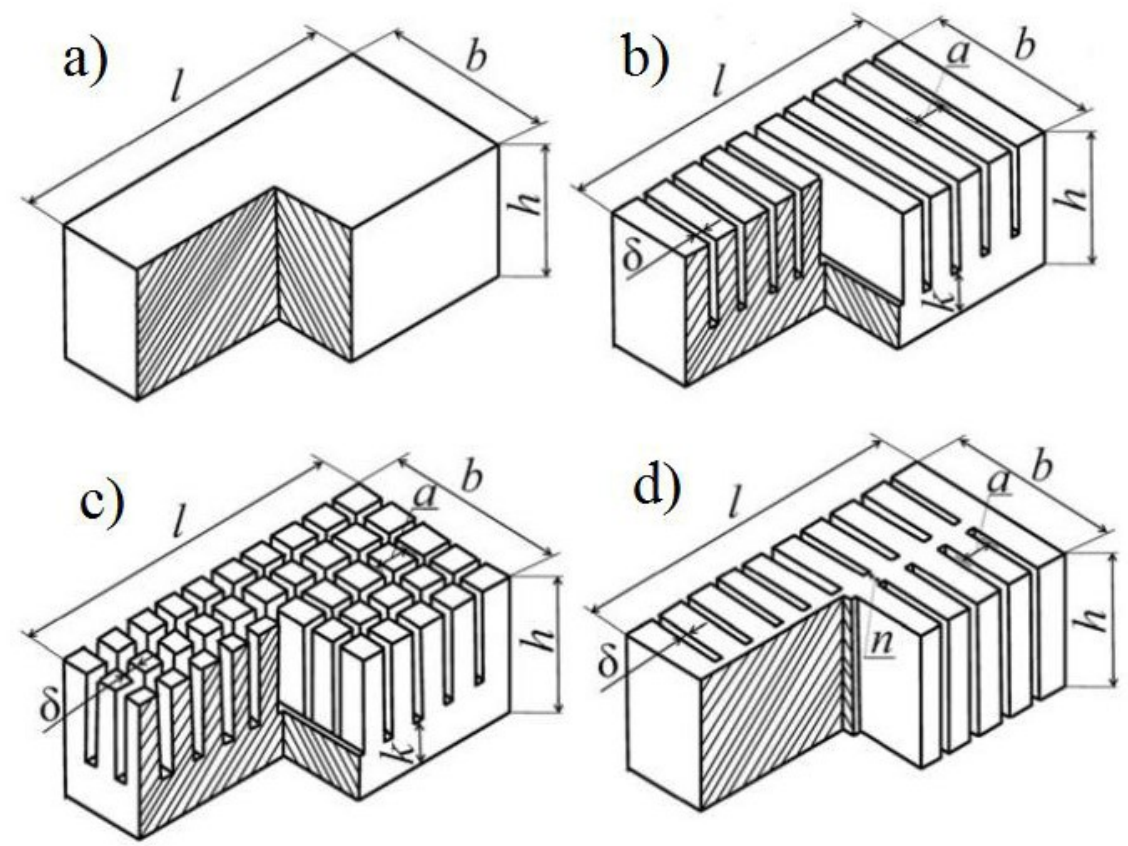

Fig.-3: Forms of Single PUF-Peter Samples studied by the Authors. Isometric view with $1 / 4$ neckline.

$l=50 \mathrm{~mm}, b=25 \mathrm{~mm}, h=20 \mathrm{~mm}, a=5 \mathrm{~mm}, \delta=1 \mathrm{~mm}, k=7 \mathrm{~mm}, n=5 \mathrm{~mm}$

Even this was evidence of the fact that the glassy nature of the oil sorbents surface was a necessary but insufficient condition for the existence of peaks on the oil absorption kinetic curves. At the same time, the use of at least two samples of form a) (Fig.-3) that in the course of the experiment at planes were in contact with a surface with area $l h$ resulted in the existence of peaks on the oil absorption kinetic curves. This indicates that the presence of a peak required absorption due to the capillary forces in the porosity space between the samples.

It is important to note that the use of various rigid structures (Fig.-3b,c,d) with slits that ensured the existence of capillary forces did not result in peaks on the absorption kinetic curves. Thus, the appearance of peaks on the absorption kinetic curves required the formation of a coagulation type structure in which solid particles of the sorbent were bonded by the liquid layer of oil, remaining mobile.

The previously mentioned was also confirmed by the fact that in studying oil absorption by two samples of form a) (Fig.-3), oil absorption increased, and the peak on the kinetic curves became more evident with decreasing value $h$, i.e., with increasing the approximation to the observed coagulation structure.

Further studies of PUF as oil sorbents were continued on the samples obtained in the laboratory conditions with various technological formulation parameters. All studies of both industrial samples of PUF and the samples synthesized in the laboratory performed before April 2017 were generalized in the dissertation ${ }^{24}$ compiled under the scientific supervision of Professor V. E. Kogan.

In the laboratory conditions, PUF was synthesized at the temperatures of $20,30,40,50,60$, and $70^{\circ} \mathrm{C}$ in a cylindrical reactor made of polypropylene placed on a water bath, where the temperature was regulated with the accuracy of \pm 1 degree. The synthesis was made from component A (polyol) — saturated polyester PolyKhim-2001 R-7/1 (PE KHIMPOSTAVSCHIK, Ukraine) - and component B polyisocyanate based on 4.4-methylene diphenyl diisocyanate Cosmonate M-200 (KUMNO MITSUI CHEMICALS, INC., Korea). Components A and B were added into the reactor in equal amounts, and, upon reaching temperature stabilization, were stirred at 300-500 rpm. At the end of the reaction, the PUF samples were air-cooled and mechanically cleaned from the surface "crust". The reaction end was considered to be the moment the volume of the PUF stopped growing. To study the kinetics of oil and diesel fuel absorption, samples with the fraction size of 3-8 $\mathrm{mm}$ were used. In all cases, peaks were 
RASĀYAN J. Chem.

Vol. 14 | No. 3 |2006-2016| July - September | 2021

observed on the absorption kinetic curves, which were similar to those for the sorbents made of foam glass with the fraction size of 3-8 $\mathrm{mm}$. During PUF synthesis, which combined the physical and chemical foaming methods, the same volumetric ratios of the same reactants were used as in the physical foaming method described above, and optionally water. The water ensured the implementation of one of the techniques of the foaming chemical method ${ }^{25}$-the in situ reaction between the two reactants with the release of gas, namely, the reaction of terminal isocyanate groups with water, which resulted in carbon dioxide generation.

The peculiarity of the PUF obtained by combining physical and chemical foaming methods is the fact that when a certain amount of water is contained in the reaction mixture, the peaks on the kinetic curves of oil and diesel fuel absorption disappear, and the kinetic curves have the well-known nature for oil sorbents, i.e., an increase in oil and diesel fuel absorption with subsequent saturation is noted. The aforesaid is illustrated by Fig. -4 a, b, curves 4 on the example of the kinetic curves of oil and diesel fuel absorption by the samples of foam obtained at $70^{\circ} \mathrm{C}$ from the reaction mixture containing $6.25 \%$ of water (over $100 \%$ by volume).

One possible reason for such a result could be the absence of a glassy surface on these PUF samples. However, the X-ray analysis showed that all synthesized samples were X-ray amorphous. The obtained result was explained by an electronic microscopic examination (Figure 5). The PUF samples obtained at $70^{\circ} \mathrm{C}$ from the reaction mixture containing $6.25 \%$ of water (more than $100 \%$ by volume) were characterized by the presence of many open macropores on the surface, which prevented capillaries formation in the porosity space between the samples, and hence the coagulation structure.

a)

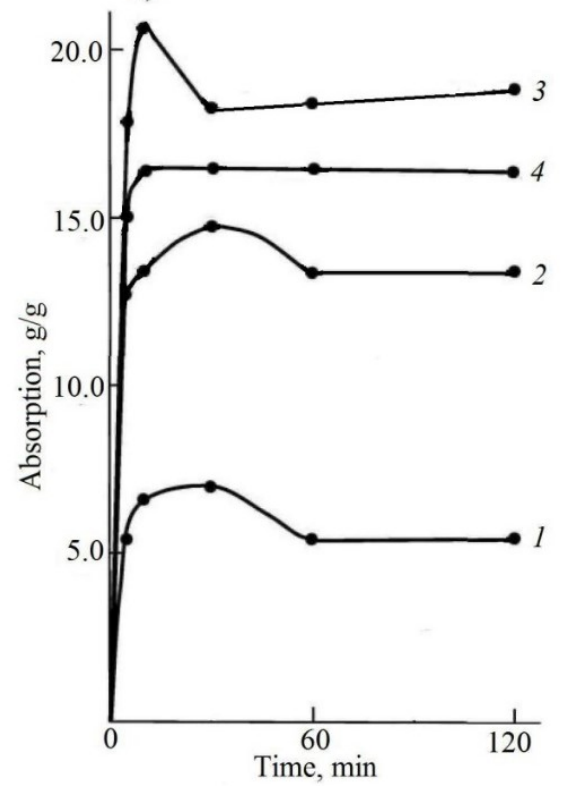

b)

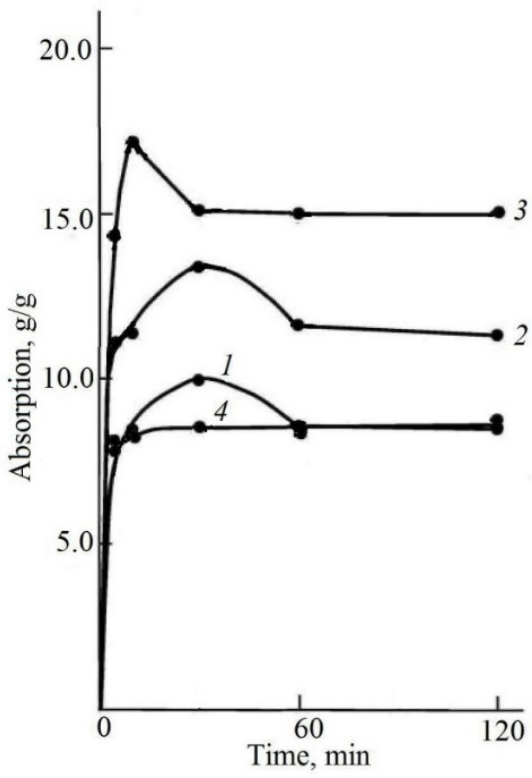

Fig.-4: Kinetics of Absorption of oil (a) and Diesel Fuel (b) by the Sorbents from PUF Fraction of 3-8 mm, synthesized at $70^{\circ} \mathrm{C}$ with a Combination of Physical and Chemical Foaming Methods. The Water Content in the Reaction Mixture (over $100 \%$ by volume): $1-2.50 \%, 2-3.75 \%, 3-5.00 \%$, and $4-6.25 \%$

For the synthesis of composite sorbents based on PUF $24,26,27$, the authors chose the polyurethane synthesized at $70^{\circ} \mathrm{C}$ from the reaction mixture containing (more than $100 \%$ by volume) $5.00 \%$ of water, characterized by the highest absorption of both oil and diesel fuel (figures $4 \mathrm{a}, \mathrm{b}$, curves 3 ) as the base. Conversion of this reaction mixture to $100 \mathrm{wt}$. \% gave the following composition: $48.54 \%$ of component A, $47.58 \%$ of component $\mathrm{B}$, and $3.88 \%$ of $\mathrm{H}_{2} \mathrm{O}$. To obtain composite oil sorbents, $9.71 \%, 19.41 \%$, $38.83 \%$, and $77.66 \%$ of phosphogypsum (over $100 \mathrm{wt}$. \%) were introduced into this reaction mixture.

Unlike the basic PUF (Fig.-4 a, b, curves 3), for the composite PUFs synthesized at $70^{\circ} \mathrm{C}$, the kinetic oil and diesel fuel absorption curves with all contents of phosphogypsum in the reaction mixture have the well-known nature for oil sorbents, i.e., increased absorption of oil and diesel fuel with subsequent 
saturation was observed. The absence of peaks on the oil and diesel fuel absorption curves seemed natural to the authors. The introduction of crystalline filler (phosphogypsum) into the composition of the reaction mixture fails to meet even the necessary condition for peak occurrence (not to mention the necessary and sufficient condition). Indeed, as shown by the X-ray diffraction analysis, X-ray diffraction peaks were observed for all samples of PUF containing phosphogypsum in the reaction mixture (with the $2 \Theta$ angular orientation shown above them in Fig.-6).

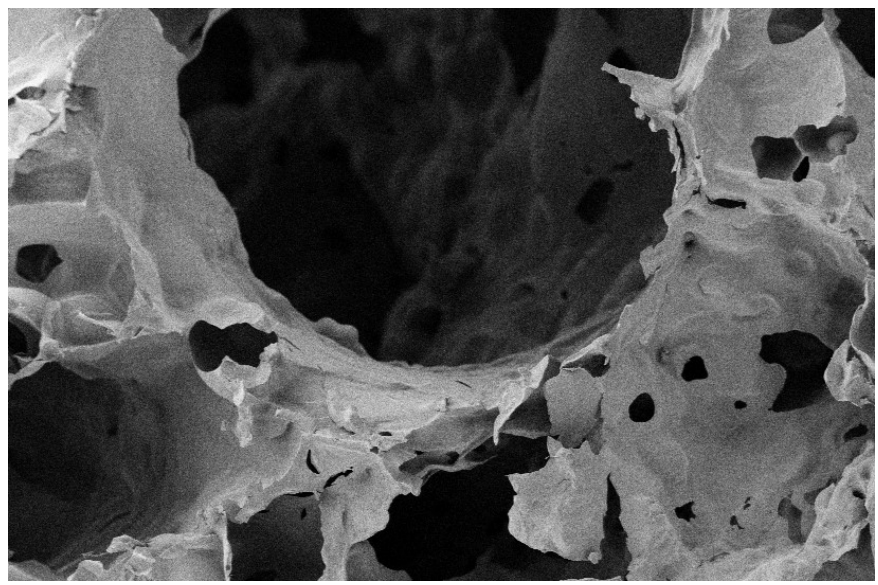

Fig.-5: Electronic Photo of the PUF Sample synthesized at $70^{\circ} \mathrm{C}$ from a Reaction Mixture containing (over $100 \%$ by volume) $6.25 \%$ water. Magnification $100 \mathrm{X}$

It should be noted that when the content of phosphogypsum in the reaction mixture (over $100 \mathrm{wt} . \%$ ) was 9.71\% and $19.41 \%$, two diffraction peaks related to PUF (marked as PUF above them in Fig.-6 a, b) were observed. The presence of diffraction peaks related to PUF is most probably because the crystal particles of phosphogypsum introduced during the preparation of the reaction mixture into component A got solvated by it, which caused the orientation of polyol, and, therefore, of all subsequent compounds in the polymer mass formed during reaction with it.
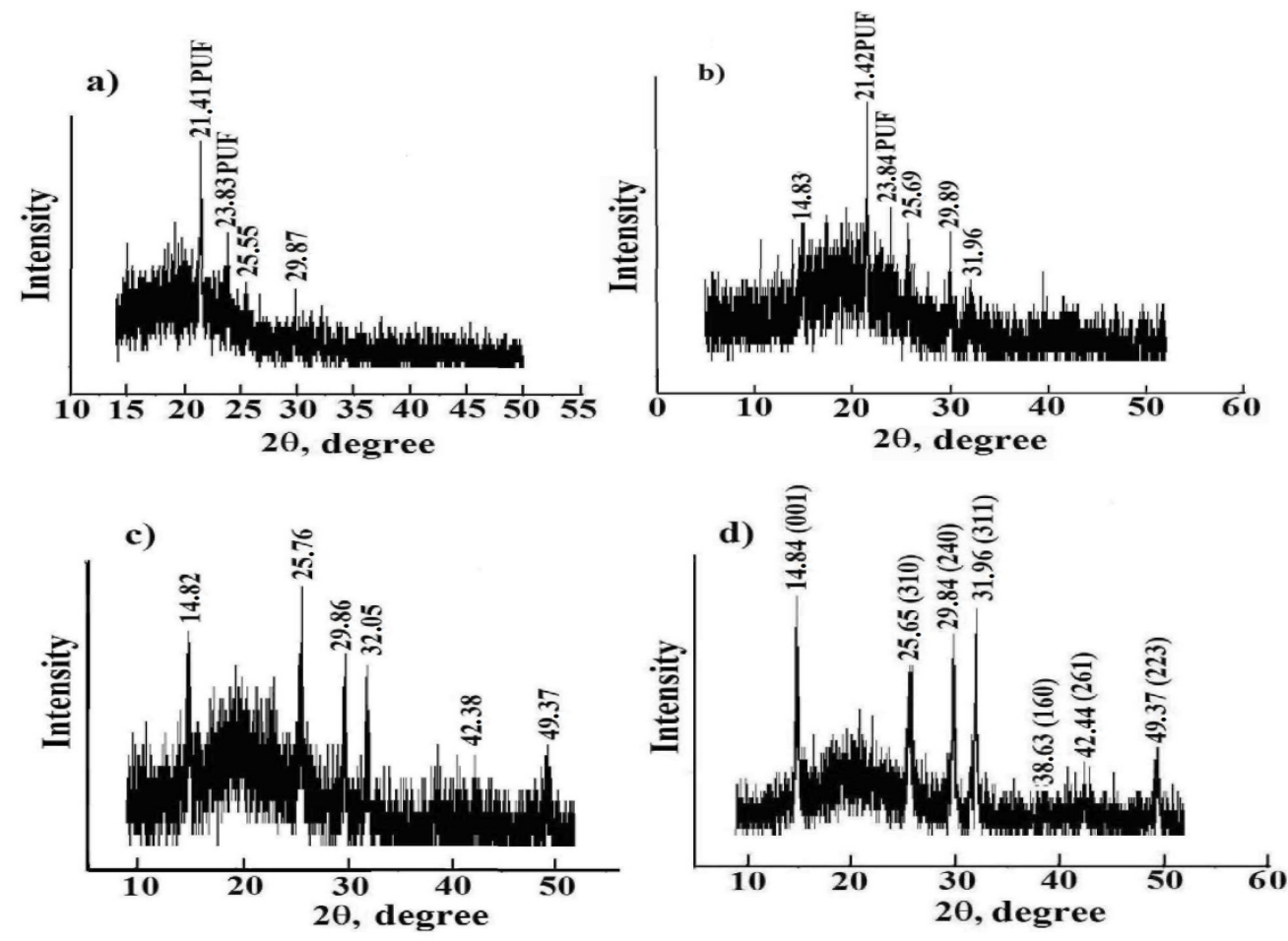

Fig.-6: X-ray Spectrums of the PUF Samples synthesized at $70^{\circ} \mathrm{C}$. The Content of Phosphogypsum in the Reaction mixture (in excess of 100 mass \%): (a) $9.71 \%$; (b) $19.41 \%$; (c) $38.83 \%$; and (d) $77.66 \%$ 
Increasing the content of phosphogypsum in the reaction mixture (over $100 \mathrm{wt} \%$ ) decreases the maximum oil capacity and the maximum storage capacity for diesel fuel. This is most probably due to the decrease in the share of mesopores that are responsible for oil and oil products absorption ${ }^{14}$, in the structure of the composite oil sorbents with increasing the content of phosphogypsum in the reaction mixture.

Work $^{24}$ shows experimental results of measuring the surface area and the porosity of four PUF samples synthesized at $70^{\circ} \mathrm{C}$ : PUF 1 (water content $6.25 \%$ ), PUF 2 (water content $5.00 \%$ ), PUF 3 (phosphogypsum content $77.66 \%$ ), and PUF 4 (phosphogypsum content $38.83 \%$ ). The analysis of these results in this work allowed us to determine the volume share of mesopores, \%. The obtained results, the maximum oil capacity, and the maximum capacity for diesel fuel of these four PUFs are shown in Table1 .

Table-1: Volume Share of Mesopores, the Maximum Oil Capacity, and the Maximum Capacity for Diesel Fuel for

\begin{tabular}{c|c|c|c|c|}
\hline \multicolumn{7}{|c|}{ PUF Samples } \\
\hline PUF Type & PUF 1 & PUF 2 & PUF 3 & PUF 4 \\
\hline Volume share of mesopores, \% & 52.04 & 57.45 & 51.46 & 58.98 \\
\hline Maximum oil capacity, g/g & 16.82 & 20.78 & 8.31 & 13.77 \\
\hline Maximum capacity for diesel fuel, g/g & 8.86 & 17.33 & 7.24 & 12.41 \\
\hline
\end{tabular}

As one can see in the Table, for glassy PUFs (PUF 1 and PUF 2), regardless of the presence of a peak on the oil and diesel fuel absorption kinetic curves, an increase in the maximum oil capacity and the maximum capacity for diesel fuel with increasing the volume share of mesopores was observed, which correlated with the above results for the oil sorbents based on phosphate glass. A similar result was observed in the PUF containing the crystalline phase (PUF 3 and PUF 4). At the same time, during the transition from glassy sorbents to the sorbents containing the crystalline phase, this regularity was disrupted, which was evidence of the specific effect of the glassy state on the kinetics of oil and diesel fuel absorption.

Relatively recently, the authors have started studying oil sorbents based on polystyrene foams (PSF). ${ }^{28,} 29$ Same as for all previously studied sorbents, initial studies had been performed with industrial PSF samples. To date, industrial PSF made using various technologies have been studied, namely:

1. Alphapor expandable polystyrene (EPS) of SE (Self-Extinguishing) type made by JSC SIBURKhimprom (Perm), which is available in milky-white spherical semitransparent particles $(2 \mathrm{~mm}$ and 4-5 $\mathrm{mm}$ in diameter, with an apparent density of 15 and $8-9 \mathrm{~kg} / \mathrm{m}^{3}$, respectively);

2. PSF made by Parkon Plus LLC (St. Petersburg) using the method without press from Alphapor polystyrene according to p.1 - PSF from Parkon Plus LLC (in the experiments, 3, 5, and $8 \mathrm{~mm}$ cubes were used cut from PSF with the apparent densities of 8 and $35 \mathrm{~kg} / \mathrm{m}^{3}$ );

3. Two types of PSF obtained using the extrusion method (XPS):

-XPS TECHNONICOL CARBON ECO (TECHNONIKOL) made by TECHNONIKOL Corporation (in the experiments, 3,5 , and $8 \mathrm{~mm}$ cubes cut from plates with the apparent densities of $26-32 \mathrm{~kg} / \mathrm{m}^{3}$ were used); and

-Comfort expanded polystyrene manufactured by PE Penoplex (Novosibirsk) (in the experiments, 3,5 , and $8 \mathrm{~mm}$ cubes cut from plates with the apparent density of $25-35 \mathrm{~kg} / \mathrm{m}^{3}$ were used).

The oil and diesel fuel absorption kinetic curves are well known. One of the possible reasons for the absence of peaks on the kinetic curves could be the fact that the studied materials were characterized by crystallinity, i.e., the necessary condition for peaks existence of the oil and diesel fuel absorption kinetic curves-the glassy nature of the surface of oil sorbents-did not exist.

However, X-ray analysis showed that all studied PSF samples were X-ray amorphous. At the same time, survey X-rays of the PSF samples from Parkon Plus LLC with the apparent density of $35 \mathrm{~kg} / \mathrm{m}^{3}$ and from TECHNONIKOL with the apparent density of $26-32 \mathrm{~kg} / \mathrm{m}^{3}$ showed a halo in the area of small angles $2 \theta$ (up to $20^{\circ}$ ), which was evidence of X-rays interference on numerous pairs of atoms or molecules located at equal distance $\mathrm{S}$ from each other, which was determined using the known Kersom-Smith formula. Therefore, X-ray graphs of these samples were made in detail in small increments of $\Delta(2 \theta)=0.01^{\circ}$ : in the range of small angles $2 \theta\left(5^{\circ}\right.$ to $\left.35^{\circ}\right)$ for the PSF samples from Parkon Plus LLC and TECHNONICOL (Fig.-7). 
RASĀYAN J. Chem.

Vol. 14 | No. 3 |2006-2016| July - September | 2021

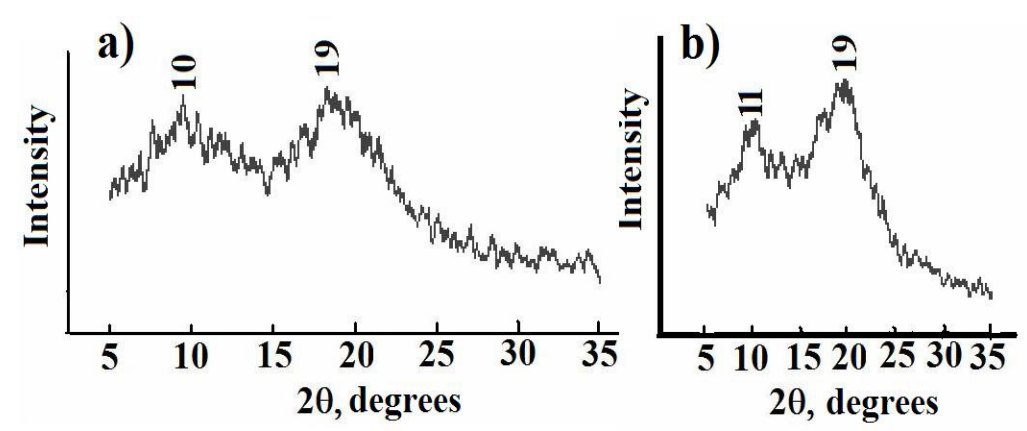

Fig.-7: X-ray Spectrums of Samples of PSF from Parkon Plus LLC with the apparent density of $35 \mathrm{~kg} / \mathrm{m}^{3}$ (a) and PSF from TECHNONICOL with the apparent density of $26-32 \mathrm{~kg} / \mathrm{m}^{3}(\mathrm{~b})$

On the X-ray graphs (Fig.-7), two halos were observed: at angles $2 \theta$ equal to $10^{\circ}$ and $19^{\circ}$ (for the PSF from Parkon Plus LLC) and $11^{\circ}$ and $19^{\circ}$ (for the PSF from TECHNONIKOL), which corresponded to two intermolecular distances $S=10.8 \AA$ and $S=5.8 \AA$, calculated using the known Kersom-Smith formula. It is important to note that the intermolecular distance $S=5.8 \AA$, as noted in works ${ }^{30,31}$, corresponds to the distance between the benzene rings.

Given the fact that the polystyrene (PS) obtained by free-radical polymerization in a solution is atactic, the considered result might be interpreted as a tendency to the manifestations of long-range order, which, as is known, is not characteristic of glassy materials.

It should be emphasized here that PS with its linear structure, and, consequently, the surface of PSF cannot be considered a true glassy state identical to that of inorganic glass. For it, one cannot state unambiguously the absence of the long-range order, and, at the same time, chemical microinhomogeneity substantiated, in particular, for inorganic glass by R. L. Muller ${ }^{32,33}$ is impossible. At the same time, it is the microinhomogeneity of the structure that results in a nonequipotential surface that increases the capillary potential in the capillaries with a vitreous surface (in particular, in the porosity space between the samples), and ensures the presence of peaks on the oil and oil products absorption kinetic curves.

That said, future studies would be focused on developing a technology for obtaining sorbents based on linked vinyl PSs and other vinyl polymers with a meshed structure that is similar to inorganic glass. If the conclusions are correct, one can expect peaks on the oil and oil product absorption kinetic curves.

\section{CONCLUSION}

Based on the studies of the physicochemical fundamentals of oil and petroleum absorption by glassy sorbents that were for the first time performed at the Department of General Chemistry of the St.Petersburg Mining University, the presence of the specifics of the kinetic curves of absorption by glassy surface sorbents has been established, and the following conclusions have been drawn:

1. The vitreous surface state of the oil sorbents based on both inorganic and organic materials is a necessary condition for the existence of a peak in the initial period on the oil and oil products (diesel fuel) absorption kinetic curves.

2. The vitreous state of the surface of oil sorbents based on both inorganic and organic materials and the mechanism of oil absorption due to the capillary forces in the porosity space between the samples that form a coagulation structure, i.e., being connected by a layer of oil, remain stationary, constitute a necessary and sufficient condition for the existence of peaks on the oil and oil products (diesel fuel) absorption kinetic curves in the initial period.

3. Increasing the degree of chemical microheterogeneity of glassy oil sorbents based on both inorganic and organic materials increases the height of a peak on the oil and oil products (diesel fuel) absorption kinetic curve. This is most probably due to the increase in the nonequipotential surface, which increases the capillary potential in the capillaries with the vitreous surface (in particular, in the porosity space between the samples).

4. The maximum oil absorption of the sorbents is a function of the volume share of micro-and mesopores. Increasing the mesopores volume concentration (decreasing the volume concentration of micropores) increases the oil and diesel fuel capacity of the sorbents. 
RASĀYAN J. Chem.

Vol. 14 | No. 3 |2006-2016| July - September | 2021

5. Amorphous organic sorbents with linear structure cannot be considered as truly glassy and identical to inorganic glass, which leads to manifestations of the kinetic absorption curves identical for all oil sorbents studied before this study.

\section{ACKNOWLEDGEMENT}

The authors are grateful to all employees, postgraduates, and students that participated in the experiments.

\section{REFERENCES}

1. A.T. Hoang, X.P. Nguyen, X.Q. Duong, Environmental Science and Pollution Research, 28, 28876(2021), http://doi.org/10.1007/s11356-021-13775-Z

2. V.E. Kogan, P.V. Zgonnik, D.O. Kovina, V.A. Chernyaev, Glass and Ceramics, 70(11-12), 425(2014), http://doi.org/10.1007/s10717-014-9594-1

3. D. Peng, S. Cheng, H. Li, X, Guo, Chemosphere, 272, 129963(2021), http://doi.org/10.1016/j.chemosphere.2021.129963

4. V.E. Kogan, P.V. Zgonnik, D.O. Covina, 2013, Neftesorbenty iz penostekla i kinetika neftepogloshcheniya [Foam glass oil sorbents and the kinetics of oil absorption], in: Theory and Practice of Modern Science. Vol. II. Scientific information and publishing center Institute of Strategic Studies, Publishing house Spetskniga, Moscow, pp. 36-41.

5. B.S. Semukhin, A.V. Votinov, O.V. Kazmina, Russian Physics Journal, 63(4), 710(2020), http://doi.org/10.1007/s11182-020-02088-2

6. O.G. Dolgikh. Ph.D. Thesis, Sevkav STU, Stavropol-Krasnodar (2011).

7. A. Levchuk, Ph.D. Thesis, KubSTU, Krasnodar (2012).

8. A. Temirkhanov, Ph.D. Thesis, KubSU, Krasnodar (2005).

9. V.E. Kogan, P.V. Zgonnik, T.S. Shakhparonov, D.O. Kovina, Actual problems of humanitarian and natural sciences: Monthly Scientific Journal, 4(63), 33(2014).

10. A. Gafiullina, V.E. Kogan, P.V. Zgonnik, T.S. Sakhparonova, International Research Journal, 2(33), 9(2015).

11. V.E. Kogan, P.V. Zgonnik, A.A. Gafiullina, V.E. Kogan, P.V. Zgonnik, T.S. Sakhparonova, Oil Industry, 8, 125(2015).

12. V.E. Kogan, P.V. Zgonnik, T.S. Shahparonova, D.O. Kovina, International Research Journal, 11(42), 50(2015).

13. V.E. Kogan, A.A. Gafiullina, P.V. Zgonnik, International Journal of Applied Engineering Research, 11(9), 6155(2016).

14. V.E. Kogan, In Proceedings of the 63th All-Russian scientific-practical conference with international participants "Actual problems of chemical and ecological education", SaintPetersburg, Russia, pp. 379-383 (2016).

15. V.E. Kogan, P.V. Zgonnik, T.S. Shakhparonova, D.O. Bogatenko, International Research Journal, 4(46), 146(2016).

16. V.E. Kogan, Proceedings of the Mining Institute, 218, 331(2016).

17. V.E. Kogan, T.S. Shakhparonova, D.O. Kovina, In Proceedings of the 16th International Multidisciplinary Scientific GeoConference SGEM 2016, June 28 - July 6, Albena, Bulgaria, 5(2), pp. 603-610 (2016).

18. V.E. Kogan, T.S. Shakhparonova, D.O. Sobianina, In Proceedings of the 18th International Multidisciplinary Scientific GeoConference SGEM 2018, 2 July - 8 July, Albena, Bulgaria, SGEM, 18(5.1), pp. 831-836 (2018).

19. V.E. Kogan, International Journal of Mechanical Engineering and Technology, 9(12), 1232(2018).

20. G.O. Karapetyan, K.G. Karapetyan, V. E. Kogan, In Proceedings of the anniversary scientific conference of RF AES, Saint Petersburg, Russia, pp. 15-18 (2001).

21. V.E. Kogan, K.G. Karapetyan, Polikristallicheskie i stekloobraznye fosforsoderzhashchie udobreniya [Polycrystalline and glassy phosphorus-containing fertilizers], LEMA, Saint Petersburg (2015). 
RASĀYAN J. Chem.

Vol. 14 | No. 3 |2006-2016| July - September | 2021

22. V.E. Kogan, P.V. Zgonnik, A.V. Chernyaev, Actual Problems of Humanitarian and Natural Science: the Monthly Scientific Magazine, 5(52), 26(2013).

23. V.E. Kogan, P.V. Zgonnik, T.S. Shakhparonova, A. V. Chernyaev, International Research Journal, 5(47), 104(2016).

24. V.A. Chernyaev, Ph.D. Thesis, St. Petersburg State Technical Institute (Technical University), Saint Petersburg, Russia (2017).

25. T.G. Chatzimitakos, C.D. Stalikas, Molecules (Basel, Switzerland), 25(16) (2020), http://doi.org/10.3390/molecules25163673

26. V.E. Kogan, P.V. Zgonnik, V. A. Chernyaev, International Journal of Civil Engineering and Technology, 9(13), 963(2018).

27. V. Perfiliev, Vestnik of the Far East Branch of the Russian Academy of Sciences, 5, 142(2010).

28. V.E. Kogan, P.V. Zgonnik, T.S. Shakhparonova, Z. V. Suvorova, International Research Journal, 6(60), 88(2017).

29. V.E. Kogan, P.V. Zgonnik, T.S. Shakhparonova, Z.V. Suvorova, International Journal of Mechanical Engineering and Technology, 9(12), 1267(2018).

30. P. Russo, Handbook of X-ray Imaging: Physics and Technology, CRC Press, Boca Raton (2018).

31. P. Nanjan, M. Porel, Polymer Chemistry, 10, 5406(2019), http://doi.org/10.1039/C9PY00886A

32. R.L. Mueller, Khimiya tverdogo tela i stekloobraznoe sostoyanie [Solid chemistry and glassy state], Solid chemistry-Leningrad, Leningrad State University, Leningrad, pp. 9-63 (1965).

33. R.L. Mueller. Elektroprovodnost stekloobraznykh veshchestv [Electric conductivity of vitreous substances], Leningrad State University, Leningrad (1968).

[RJC-5750/2020] 